\title{
Influence of interferometric cross talk in a cascade of 10-Gbit/s wavelength routers and an improved Gaussian cross talk model
}

\author{
Liu, Fenghai; Rasmussen, Christian Jørgen; Pedersen, Rune Johan Skullerud
}

Published in:

Lasers and Electro-Optics, 1998. CLEO 98. Technical Digest. Summaries of papers presented at the Conference on

Link to article, DOI:

10.1109/CLEO.1998.676221

Publication date:

1998

Document Version

Publisher's PDF, also known as Version of record

Link back to DTU Orbit

Citation (APA):

Liu, F., Rasmussen, C. J., \& Pedersen, R. J. S. (1998). Influence of interferometric cross talk in a cascade of 10Gbit/s wavelength routers and an improved Gaussian cross talk model. In Lasers and Electro-Optics, 1998. CLEO 98. Technical Digest. Summaries of papers presented at the Conference on (pp. 318-319). IEEE. https://doi.org/10.1109/CLEO.1998.676221

\section{General rights}

Copyright and moral rights for the publications made accessible in the public portal are retained by the authors and/or other copyright owners and it is a condition of accessing publications that users recognise and abide by the legal requirements associated with these rights.

- Users may download and print one copy of any publication from the public portal for the purpose of private study or research.

- You may not further distribute the material or use it for any profit-making activity or commercial gain

- You may freely distribute the URL identifying the publication in the public portal 


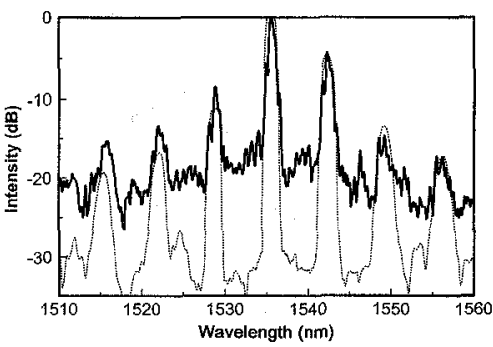

CWT2 Fig. 2. Measured (solid line) and calculated (dotted line) spectra of a demultiplexer with a constant stitching error resulted from FIB gain calibration error of $0.2 \%$, which was intentionally introduced in the writing of the grating. The field size was $52 \mu \mathrm{m}$.

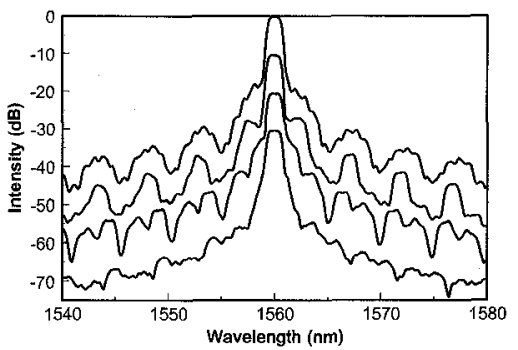

CWT2 Fig. 3. Simulated spectra for a maxi mum stitching error of $50 \mathrm{~nm}$ with different random sequences. The field size is $80 \mu \mathrm{m}$. For clarity the curves are displaced vertically by $10 \mathrm{~dB}$ from each other.

stitching error between adjacent fields. Further, the gain parameter controlling the FIB deflection amplitude needs to be calibrated in relation to the stage movement. A gain calibration error produces a constant stitching error.

We have developed a model that simulates the spectral characteristics of the demultiplexer including all of the above defects of the grating. It was found that constant stitching errors produce decaying periodic satellite peaks (Fig. 2). Random stitching errors resulting from stage movement inaccuracies can produce shoulders on both sides of the main peak, in addition to decaying irregular sidelobe structures (Fig. 3). For a field size of $80 \mu \mathrm{m}$ and a maximum stitching error of $50 \mathrm{~nm}$, the cross talk between adjacent channels can vary from -15 to $-25 \mathrm{~dB}$. This is in agreement with most of the spectra measured experimentally.

The pixelation effect due to the step size limit in the writing of the grating can produce a high background level that does not decrease in intensity with distance from the main peak. ${ }^{6}$ This ultimately determines the limit of achievable cross talk level if the stitching errors as well as the background due to stray light are eliminated. A step size of $25 \mathrm{~nm}$ produces a background level of about $-32 \mathrm{~dB}$. By writing the grating with a state-of-the-art e-beam machine with a step size $<5 \mathrm{~nm}$, a wavelength demultiplexer with cross talk of $<-45 \mathrm{~dB}$ is possible in principle.

1. J.B.D. Soole et al., Appl. Phys. Lett. 58, 1949-1951 (1991).

2. C. Cremer et al., IEEE Photonics Technol. Lett. 4, 108-110 (1992).
3. M. Fallahi et al., IEEE Photonics Technol. Lett. 5, 794-797 (1993).

4. S.M. Ojha et al., Electron. Lett. 29, 805807 (1993).

5. M.K. Smit, IEEE J. Sel. Top. Quantum Electron. 2, 236-250 (1996).

6. J.-J. He et al., submitted to IEEE J. Lightwave Technol.

\section{CWT3} 5:00 pm

Influence of interferometric cross talk in a cascade of 10-Gbit/s wavelength routers and an improved Gaussian cross talk model

Fenghai Liu, Christian J. Rasmussen, Rune J.S. Pedersen, Department of Electromagnetic Systems, Building 348, Technical University of Denmark, DK-2800, Lyngby, Denmark; E-mail:lf@emi.dtu.dk

Integrated optical $\mathrm{N} \times \mathrm{N}$ wavelength routers based on arrayed-waveguide gratings (AWGs) are likely to become key devices in future wavelength-division multiplexing (WDM) networks..$^{1,2} \mathrm{~A}$ cascade of wavelength routers is formed when several $\mathrm{N} \times \mathrm{N}$ networks are interconnected as shown in Fig. 1. Due to the nonideal transfer function of physical AWGs, a node will receive not only the signal from the node it is connected to, but also cross talk at the same wavelength from the other nodes. In a cascade of AWG routers, the cross talk will accumulate and thereby limit the number of stages. The Gaussian cross talk model is considered to be a worst-case model when investigating multiple independent cross talk sources, ${ }^{2-4}$ but higher power penalties than predicted by this model is found in Ref. 4 as well as in our work. We extend the model by including the signal extinction ratio and spontaneous emission from the optical preamplifier in our receiver. Experimentally, a recirculating loop is used for investigation of router cascades. Very good agreement is demonstrated between the measured penalty and the penalty predicted from our improved Gaussian cross talk model.

In our cross talk model, which includes signal-cross talk beat noise and signalspontaneous emission beat noise, we assume that (1) the signal and all the cross talk contributions have the same polarization state (worst case); (2) the noise contributions are independent and can be described by Gaussian probability density functions; (3) optimized threshold is used. This leads to a new equation for power penalty versus relative cross talk $\varepsilon$ and signal extinction ratio $r$ :

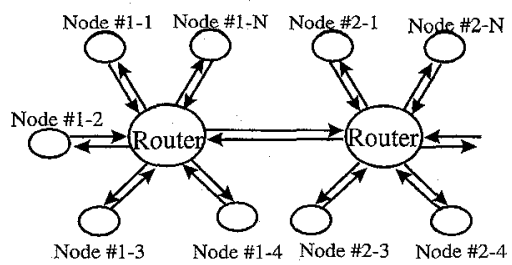

CWT3 Fig.1. Architecture of network using a cascade of routers.

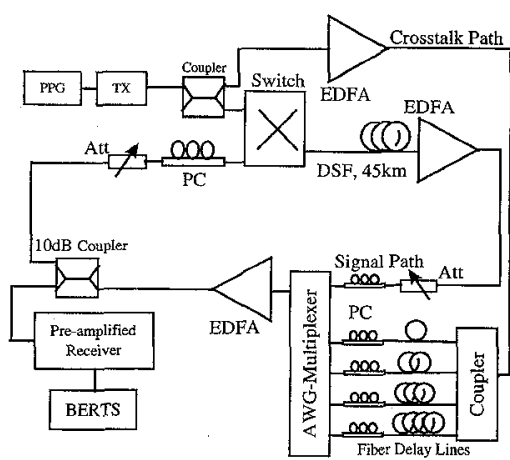

CWT3 Fig. 2. Experimental setup for measuring the cascadability of routers. PPG: pulse pattern generator. TX: transmitter. Att: attenuator. PC: polarization controller. BERTS: biterror-rate test set. DSF: dispersion-shifted fiber. AWG: arrayed waveguide grating.

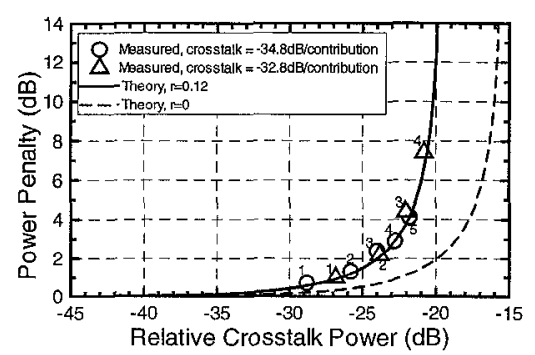

CWT3 Fig. 3. Relation between power penalty and relative cross talk power. The number related to the symbols indicates the loop round trips corresponding to the number of cascaded AWG routers.

$$
\operatorname{Penaliy}(d B)=-10 \log \left[1-\frac{(1+r) Q^{2} \varepsilon}{(1-\sqrt{r})^{2}}\right]
$$

$Q$ is equal to 6 at $\mathrm{BER}=10^{-9}$.

Figure 2 shows the recirculating loop setup used for the investigation of the AWG router cascadability. The light from the transmitter modulated externally at $10 \mathrm{Gbit} / \mathrm{s}$ is divided into a signal part and a cross talk part. The cross talk part is amplified in an erbium-doped fiber amplifier (EDFA), split into four, and decorrelated using four fibers of different length in order to obtain independent cross talk contributions. The signal part is launched via the switch into the loop, which includes 45 $\mathrm{km}$ of dispersion-shifted fiber. Polarization controllers and an attenuator are put before the AWG router to achieve identical polarization states and approximately equal power at all inputs. The loop contains two EDFAs to compensate for the loss. A part of the signal (including cross talk) circulating in the loop is coupled into the optically pre-amplified receiver. Bit error rate is measured at optimized threshold.

Wavelength routers used in cascade should be carefully designed, because all cross talk contributions are accumulated in the cascade. Even for a low cross talk power of $-34.8 \mathrm{~dB}$ per contribution, a power penalty of $4.1 \mathrm{~dB}$ is measured when cascading five routers, each adding four cross talk contributions. The measured penalty as a function of accumulated cross talk power is shown in Fig. 3 together with the 
penalty calculated from (1) assuming an extinction ratio of 0.12 (solid). Excellent agreement between experimental result and the new Gaussian model is observed. To show the influence of the signal extinction ratio, a curve of $\mathbf{r}=0$ (dashed) is also plotted in the same figure. It can be seen that for a penalty of $1 \mathrm{~dB}$ there is a $5 \mathrm{~dB}$ difference of cross talk power. This clearly shows the importance of including the signal extinction ratio.

1. Hiroshi Takahashi et al., IEEE J. Lightwave Technol. 13, 447-455 (1995).

2. Hiroshi Takahashi, et al., IEEE J. Lightwave Technol. 14, 1097-1105 (1996).

3. E.L. Goldstein, et al., IEEE J. Photonics Technol. Lett. 6, 657-660 (1994).

4. E.L. Goldstein, L. Eskildsen, IEEE J. Photonics Technol. Lett. 7, 93-94 (1995).

CWT4

5:15 pm

Multiwavelength dynamically selective cross-connect based on fiber Bragg gratings and optical switches

Y.-K. Chen, S.-K. Liaw, ${ }^{*}$ C.-C. Lee, ${ }^{* *}$ Institute of Electro-Optical Engineering, National Sun Yat-Sen University, Kaohsiung 804, Taiwan

Multiwavelength cross-connect switch (M$\mathrm{XC}$ ) will play a key role in future optical multiwavelength wavelength-division multiplexing (WDM) networks. ${ }^{1,2}$ The importance of the M-XCs, and the closed related WDM add drop multiplexer (ADM), is that they allow the optical network to be reconfigured on a wavelength-by-wavelength basis to optimize traffic, congestion, network growth, and survivability. Conventional optical wavelengthfixed M-XCs usually consist of $\mathrm{N}$ sets of $1 \times N$ demultiplexers (demuxs) and $N \times 1$ multiplexers (muxs) in a back-to-back configuration to allow interchange of wavelength between input and output fibers in a prearranged pattern. In the meanwhile, the wavelengthsclective (i.e., rcarrangeable) M-XCs can bc implemented by adding space-division switches in the configuration. ${ }^{1}$ Recently, a dynamic wavelength-selective $\mathrm{ADM}$ comprising the reflective fiber Bragg gratings (FBGs) and optical switches (OSWs) was proposed. The system experiments of its add/drop/passthrough functionality's were also reported ${ }^{3}$ In this paper, we present a dynamically wavelength selective $\mathrm{M}-\mathrm{XC}$, extending previous concept, using the optical-circulators (OCs) and mechanical-optical-switch (OSW) pairs combined with single or multiple FBG(s) in appropriate connecting paths. Dynamically single- or multi-channel cross-connect can be realized according to the control of the switches and the FBG arrangements.

Figure 1 shows the proposed wavelengthselective M-XC. It consists of two three-port optical OCs, two $1 \times N$ mechanical OSWs, and $N$ pieces of the photoimprinting FBG chains. The center wavelength $\lambda_{i}$ of the FBG ${ }_{i}$ is designed to match the WDM-channel-signal $\lambda_{\mathrm{i}}$. For practical operations, the FBG central wavelengths should meet the ITU WDM standardization. Switching the switch-pair to proper position, the desired channel signals can be spatially cross-connected (here, passed through the FBG chain) to another fiber link.

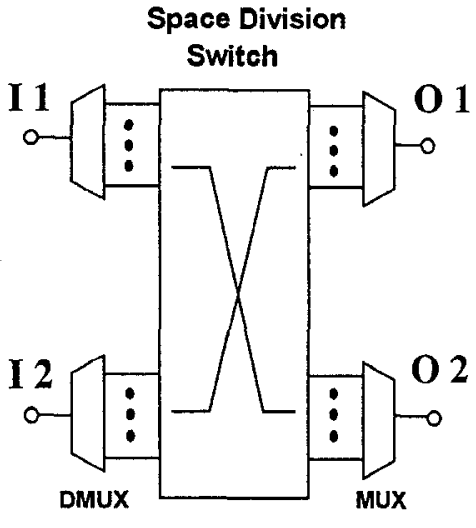

(a)

\section{M-XC}

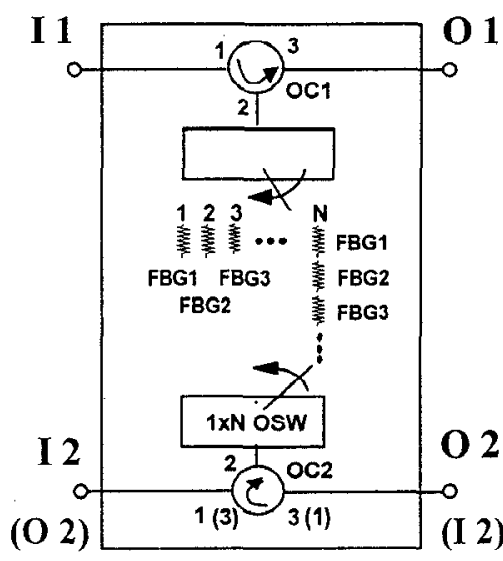

(b)

CWT4 Fig. 1. Schematic diagram of the (a) conventional and (b) dynamically selective multiwavelength cross-connect switch. OC: optical circulator. FBG: the fiber Bragg grating. OSW: the mechanical optical switch.

In the mean time, other channel signals will be reflected by the FBG chain, then leaving from the port 3 of the $\mathrm{OCl}$, and continuing its for ward propagation (here, termed as passedthrough) in the same fiber link. When two or more FBGs cascading chain is properly arranged between the switch-pair, multiple channel cross-connection can be realized. Simple $1 \times N$ mechanical OSWs can be used for this function with switching time of $0.2-1$ ms. There are two input ports 11 and 12 , and two output ports $\mathrm{O} 1$ and $\mathrm{O} 2$ of this $\mathrm{M}-\mathrm{XC}$. These two input ports can operate in the same direction or opposite direction, only by rearranging the three ports of $\mathrm{OC} 2$ clockwise or counter-clockwise, dependent on the network structures in which the $\mathrm{M}-\mathrm{XC}$ located as shown in Fig. 1.

To investigate the feasibility of this $\mathrm{M}-\mathrm{XC}$, two sets of multiwavelength transmitters externally modulated at $2.5 \mathrm{~Gb} / \mathrm{s}$ (see Fig. 2) were used. Each transmitter set comprising three distributed feedback lasers with same wavelength sets of $1547.7 \mathrm{~nm}, 1549.3 \mathrm{~nm}$, and $1550.9 \mathrm{~nm}$, respectively. The total $100-\mathrm{km}$ transmission link of conventional single-mode fiber (SMF) was arranged. Two erbium-doped fiber amplifiers (EDFAs) were employed to

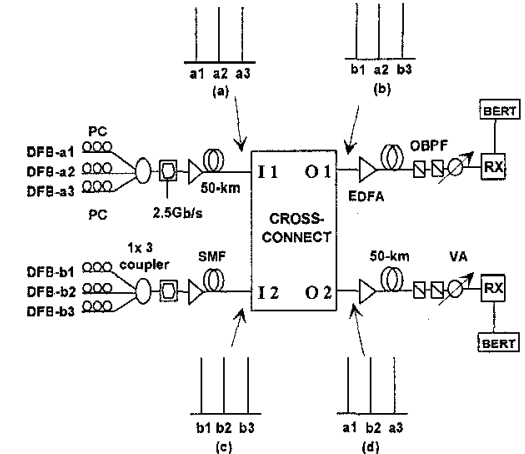

CWT4 Fig. 2. Experimental setup. EDFA: the erbium-doped fiber amplifier, VA: the variable optical attenuator. SMF: the single-mode fiber. PC: the polarization controller. RX: optical receiver. OBPF: optical bandpass filter.

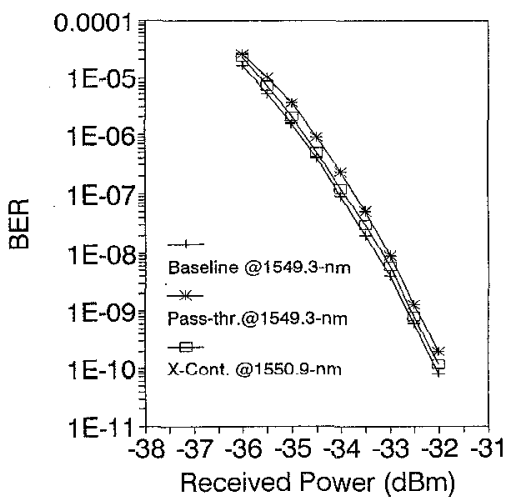

CWT4 Fig. 3. The BER performance against the received channel power for the back-to-back $(0 \mathrm{~km})$, pass-through $(100 \mathrm{~km})$ at $1549.3 \mathrm{~nm}$, and cross-connect $(100 \mathrm{~km})$ at $1550.9 \mathrm{~nm}$ cases.

provide the required power to compensate the link loss. A narrowband optical bandpass filter (OBPF) was used at the receiving end to select the desired WDM channel for detection. A PINFET receiver with a sensitivity of -32.5 $\mathrm{dBm}$ at a BER of $1 \times 10^{-9}$ was used for the BER performance testing. The averaged crossconnect (reflective- or passed-through path) insertion losses of this $\mathrm{M}-\mathrm{XC}$ are all about 3.7 $\mathrm{dB}$. The $3-\mathrm{dB}$ passband width and reflectivity of these FBGs are about $0.2 \mathrm{~nm}$ and $99 \%$, respectively. All connectors used were physical contact connectors with return loss of $<-45$ dB.

In our experiment, the optical signal-tonoise ratio were about $62 \mathrm{~dB}$ and $45 \mathrm{~dB}$ for the passed-through and cross-connected channels due to the filtering-out of the amplified spontaneous emission from EDFA by the narrow, sharp passband of the used FBG. Figure 3 shows the BER performance of the "a" set transmitters against the received channel power for the back-to-back $(0 \mathrm{~km})$, passthrough $(100 \mathrm{~km})$ at $1549.3 \mathrm{~nm}$, and crossconnect $(100 \mathrm{~km})$ at $1550.9 \mathrm{~nm}$ cases. Note that negligible power penalty of only $0.3 \mathrm{~dB}$ was observed in this $2.5 \mathrm{~Gb} / \mathrm{s} \times 6 \mathrm{WDM}$ wavelength network. The system operation and performance confirmed the feasibility of the M-XC. There are several important features for this device with potentially low cross 